[Research Paper]

효과적인 피난을 위한 보행거리 및 출구 폭에 대한 연구

\author{
임승혁 · 최승복 ${ }^{*}$ 최돈묵 ${ }^{* * \dagger}$ \\ 가천대학교 소방방재학과 대학원생, "경기북부지방경찰청 화재조사과 팀장, ${ }^{* *}$ 가천대학교 설비 · 소방공학과 교수
}

\title{
A Study on the Travel Distance and Exit Width for Securing Efficient Evacuation
}

\author{
Seung-Hyuk Im $\cdot$ Seung-Bok Choi $\cdot$ Don-Muk Choi ${ }^{* *+}$ \\ Graduate Student, Dept. of Fire Protection Engineering, Gac hon Univ., \\ *Team manager, Dept. of Fire Investigation Team of Gyeonggibukbu Provincial Police Agency, \\ ${ }^{* *}$ Professor, Dept. of Fire Protection Engineering. Gachon U
}

(Received February 16, 2021; Revised March 25, 2021; Accepted April 5, 2021)

\section{요 약}

국내 성능위주설계의 기준은 화재 시나리오 및 기타 구체적인 조건들을 제시하는 해외 기준에 비해 빈약하여 실 제와 유사한 피난시간 도출에 어려움이 있다. 이에 본 연구에서는 피난상황 발생 시, 내부 재실자가 안전하게 피난할 수 있는 합리적인 피난시간을 도출하기 위해 국내외 기준 검토 및 시뮬레이션을 통해 보행거리 및 출입구 폭에 대한 기준을 제시하고자 했다. 본 연구의 제시안은 피난동선과 출입구의 유효 폭을 적용하는 직접적인 방법과 장애물이 많은 장소나 출구가 2 개 이상인 경우 등 화재실의 특성에 맞는 피난 해석 조건을 마련함으로써 다양한 화재 시나리 오를 포괄적으로 적용할 수 있도록 제시하였다. 시뮬레이션 결과 피난 관련 요소의 측정 기준의 부재로 국내외 기준 및 본 연구에서 제시하는 제시안의 기준에 따라, 피난시간에서 큰 차이가 발생한 것으로 확인되었다. 본 논문의 결과 를 기반으로 화재 시나리오의 선정 및 피난시간 결정 요소들에 대한 측정 기준을 제시하여 내부 재실자들의 안전을 보장할 수 있는 실효성 있는 피난 설계에 대한 추가적인 연구가 필요하다고 생각된다.

\section{ABSTRACT}

With increasing industrialization, large-scale, complex, and high-rise buildings are under way; therefore, Korea's building and fire-fighting laws need to be modified to ensure the use of active measures backed by performance-based design. However, the current standard of domestic performance-based design is weaker than that of overseas standards for fire scenarios and other specific conditions. In this study, the domestic and foreign standards and simulations were reviewed to determine the criteria for walking distance and entrance width and a reasonable and safe evacuation time in the event of an evacuation situation.

Keywords : Evacuation time, Travel distance, Effective width, Simulation, Measurement criteria

\section{1. 서 론}

\section{1 연구배경 및 범위}

화재 시 건축물의 피해를 최소화하는 것이 중요하지만, 그보다 더 중요한 것은 효과적인 피난을 통해 피난자들의 피해를 최소화하는 것이다. 유효한 피난동선을 계획하기 위해서는 피난자들이 건축물의 각 부분에서 대피하는 데에 걸리는 시간을 예측해야 하기 때문에 해당 건축물의 출입 문과 복도 폭 등 피난시간의 계산에 영향을 미치는 인자들
을 검토하는 것이 중요하다.

하지만 국내법상 피난계단의 구조와 출구 폭 및 보행거 리의 기준은 단순히 수치적으로만 접근하여 유효한 피난시 간을 계산하는 데에 한계가 있다. 보행거리의 경우 구체적 인 기준이 없어 피난자의 해당 위치에서 최단거리로 피난 하는 것으로 계산하고, 출구 폭의 경우 유효 폭을 $0.9 \mathrm{~m}$ 이 상으로 해야 한다고 규정되어 있지만 유효 폭을 측정하는 구체적인 기준의 부재로 대부분 설계도면 상 출구의 가로 폭을 사용하고 있다. 이러한 측정 기준의 부재로 측정자의

Corresponding Author, TEL: +82-31-750-5716, FAX: +82-31-750-8749, E-Mail: fire@gachon.com

(c) 2021 Korean Institute of Fire Science \& Engineering. All right reserved. 


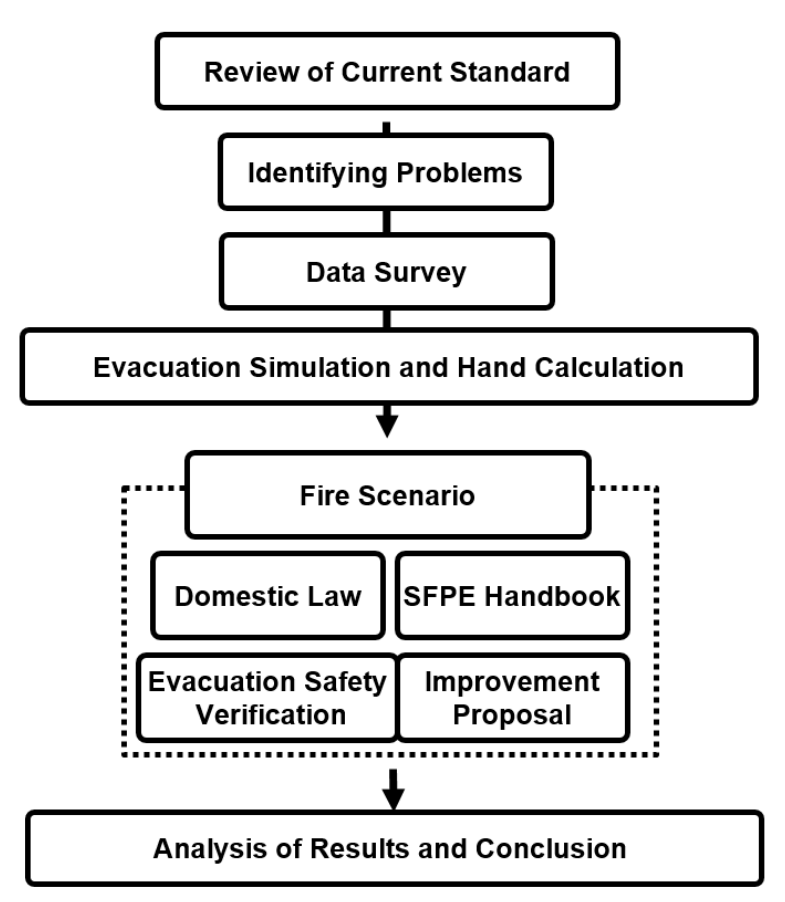

Figure 1. A method of study flow chart.

임의대로 사업자에게 유리한 방향으로 해석할 여지가 있어 피난 안전성 평가 시에 실시한 피난 시뮬레이션의 결과와 실 제 화재 상황에서의 피난시간의 괴리가 발생하게 된다. 이에 따라 본 연구에서는 신뢰성 있는 피난시간을 확보할 수 있 는 피난 방법을 제시하여 효과적인 피난을 도모하고자 한다.

\section{2 연구방법}

본 연구는 피난 시 보행거리와 출구의 유효 폭에 대한 기 준을 제시하고자 Figure 1과 같이 연구를 진행하였다. 첫째, 건축법과 소방법에 따른 피난 관련 법령을 조사하며 국내 피 난 관련 기준에 대한 문제점을 파악하고 둘째, 미국 $\mathrm{SFPE}$ Handbook과 일본 피난안전검증법에서 규정하는 피난 관련 기준에서 피난시간 계산에 영향을 미치는 인자를 도출하였 고 셋째, 국내 기준과 해외 기준을 비교 분석하고 두 가지 시 나리오에서 국내 및 해외 기준 따른 피난시간 수 계산과 시 뮬레이션을 통해 국내외 기준의 차이로 인한 결과를 확인하 였고, 마지막으로 국내 기준에 도입이 필요한 객관적이면서 도 합리적인 개선안을 제안하고 그 기준에 따른 피난 시뮬레 이션 결과를 살펴봄으로써 개선안의 정합성을 확인하였다.

\section{3 국내 기준}

본 연구에서는 연구 주제에 부합하도록 피난 관련 법령 중 피난시간에 영향을 미치는 보행거리와 출구 폭에 관련 된 조항을 발췌하여 서술하였다.

\subsection{1 보행거리 기준}

국내법에서 피난층과 연결된 직통계단과 직통계단까지
의 보행거리에 대한 기준은 「건축법 시행령」 제34조(직통 계단의 설치) (1)항 및 (2)항에서 “거실의 각 부분으로부터 계단에 이르는 보행거리"(1)로 규정하고 있어 보행거리 측 정 시 시작점에 대한 규정이 모호하고, 장애물이 있을 수 있는 공간에서도 최단거리 동선을 선택하여 보행거리를 산 정하는 등 보행거리를 측정자 임의대로 해석할 여지가 있 는 수준으로 규정하고 있다.

\subsection{2 출구 폭에 대한 기준}

출구 폭에 대한 기준은 「건축물의 피난 - 방화구조 등의 기준에 관한 규칙」제9조(피난계단 및 특별피난계단의 구 조) (2)항 1호 바목, 2호 다목, 3호 카목에서 유효 폭은 $0.9 \mathrm{~m}$ 이상 ${ }^{(2)}$ 으로 규정하고 있는데, 유효 폭에 대한 측정 기준이 표현되어 있지 않아 출입문의 단순 폭을 측정 기준으로 하 고 있는 경우가 대부분이다.

당초 고려했던 재실자의 수보다 실제 재실자의 수가 더 많거나 재해약자의 존재 및 피난자들의 패닉 현상까지 고 려하게 된다면 이러한 사소한 해석의 차이가 실제 피난 상 황에서는 큰 차이로 나타나 인명피해가 가중될 것이다.

\section{4 해외 기준}

피난관련 해외 기준은 미국 SFPE Handbook과 일본 피난 안전검증법의 내용을 검토 및 발췌하여 국내 기준과 대비 되는 특징을 서술하였다.

\subsection{1 보행거리 기준}

국내 기준인 소방시설 등의 성능위주설계 방법 및 기준 에서 규정하고 있는 화재 및 피난 시나리오는 단편적으로 화재 위치 및 상황만을 제시하고 있는 것에 비해 피난안전 검증법에서는 피난시간 계산 시에 당해 실에서 피난이 가 장 힘든 위치를 출화장소로 선정하고 화재가 근처 출구 중 가장 폭이 큰 출구를 사용할 수 없는 것으로 설정하고 있 다. 이것은 층 피난이 이뤄지는 단계에서는 화재실 출구 중 1 개소는 사용할 수 없는 상황까지 고려한 것을 나타낸다.

이처럼 해외 기준에서는 다양한 건축물에 적용할 수 있 고, 최악의 상황을 고려한 실제적인 피난시간 계산을 지향 하고 있다.

\subsection{2 출구 폭에 대한 기준}

SFPE Handbook에서는 Figure 2와 같이 유효 폭(3) 개념을 도입하여 실제와 유사한 피난상황을 제시한다. 유효 폭은 피난자들이 피난경로 요소의 전체 폭을 점유하지 않고 벽 이나 가장자리에서 약간 떨어져서 이동한다는 사실에 근거 한다. 이 개념을 도입함으로써 출구, 복도, 계단 등 피난경 로 요소 폭의 측정값보다 피난에 실제로 이용되는 폭이 작 다는 것을 감안하여 계산한다.

피난안전검증법에서는 유사한 개념인 유효 출구 폭을 도입하여 계산할 수 있다. 유효 출구 폭은 당해 실의 적재 


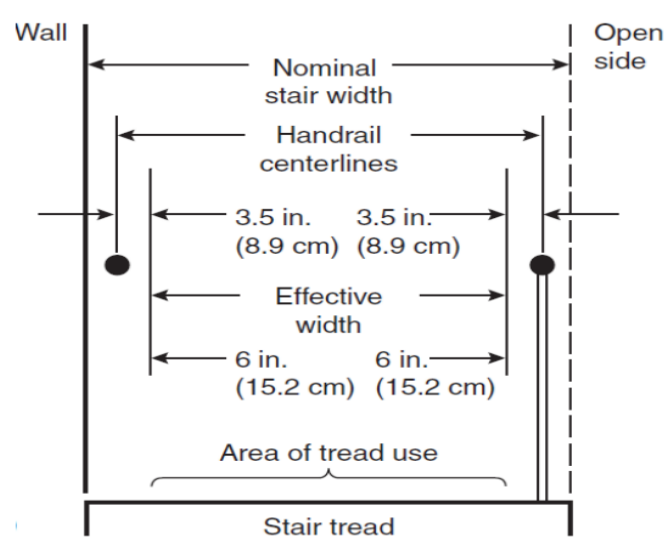

Figure 2. An example of boundary layer width ${ }^{(4)}$.

가연물의 발열량과 마감재 종류에 따른 화재 성장률을 사 용하여 계산한다.

국내와 해외 피난 관련 기준을 비교 검토한 결과, 해외 기준에 비해 국내 피난 관련 기준은 현실적이고 합리적인 피난시간을 계산하는 데에 모호한 규정을 갖고 있어서 측 정자 임의대로 해석할 여지가 있는 것을 확인할 수 있었다. 또한, 화재의 위치 및 화재의 불정형성 등을 고려하지 않아 실제 화재와의 괴리감이 있는 정형화된 화재 시나리오를 제시하고 있어 현실성 있는 피난 관련 측정 기준과 다양한 시나리오에 대한 재고가 필요한 것으로 분석되었다.

\section{2. 시뮬레이션 툴 및 시나리오 선정}

\section{1 시뮬레이터 선정}

국내 건축물의 성능위주설계 시에는 허용 피난시간 (Available safe escape time, 이하 ASET)과 소요 피난시간 (Required safe escape time, 이하 RSET)를 비교하여 건축물 의 안전성을 평가하기 위해 대부분 화재 및 피난 시뮬레이터 를 이용하여 계산하고 있다. 본 논문에서는 피난 시뮬레이션 시에 범용적으로 사용되는 SIMULEX와 Pathfinder 총 2가지 의 시뮬레이터를 사용하여 보행거리와 피난시간을 측정하였 는데, 두 가지의 시뮬레이터를 사용한 이유는 다음과 같다.

1) SIMULEX의 경우 보행거리 검토를 위해 국내 성능위 주설계 시 빈번히 이용되고 있으며, $\mathrm{CAD}$ 파일을 이용하여 시뮬레이션을 적용함으로써 가독성이 뛰어나고 피난경로, 피난자의 신체정보 등을 반영할 수 있기 때문에 보행거리 가 최대인 지점을 산정하는 데에 유용한 프로그램이다.

2) Pathfinder는 건축물의 피난 안전성 평가에서 RSET을 산정하기 위해 이용되고 있다.

위와 같이 SIMULEX를 이용하여 해당 층의 보행거리가 최대인 지점을 특정하고 Pathfinder를 이용하여 피난시간을 측정하여, 본 연구에서 살펴보고자 하는 결과 도출에 적합 한 시뮬레이터를 각각 사용함으로써 상호보완을 하고자 두 가지 시뮬레이터를 사용하였다.

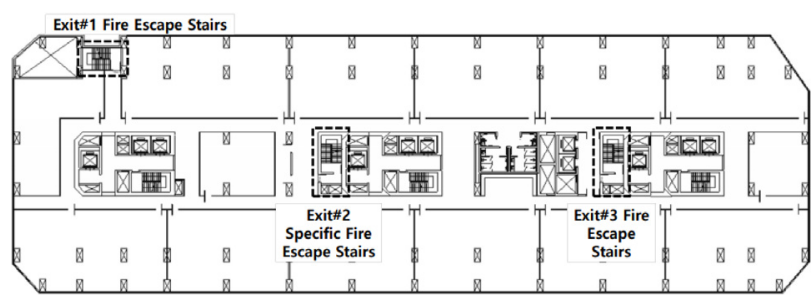

Figure 3. Business facility modeling.

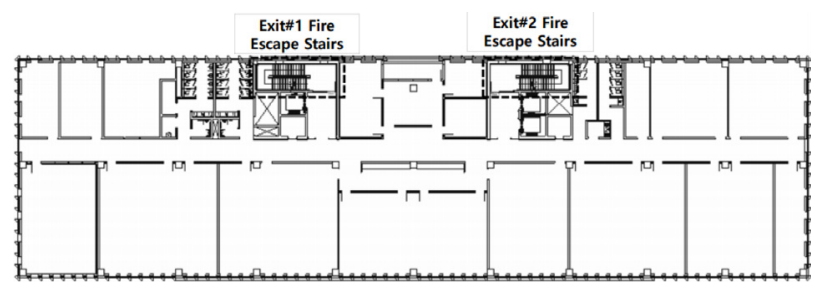

Figure 4. Sales facility modeling.

\section{2 시나리오 선정}

피난시간 비교를 위한 피난 시뮬레이션과 수 계산 대상 장소는 Figures 3,4 와 같이 본 연구의 정합성 향상을 위해 건축물에서 큰 비율을 차지하거나, 좁은 장소에 다수의 재 실자가 밀집해있는 업무시설과 판매시설로 두 가지 장소를 선정했다.

\section{3 피난시간 해석 조건}

본 연구의 목적은 보행거리와 출구 유효 폭의 측정 기준 에 따른 피난시간의 차이를 분석하고 기준을 제시하는 것 으로, 계산되는 피난시간을 실제와 근접하도록 변수를 최 소화하였다. 재실자들의 수가 많아지면 실제 화재사례와 유사한 사례일 수 있지만 앞서 서술한 피난 특성과 패닉 등으로 인한 행동 특성은 시뮬레이션으로 구현하기 어렵 고, 수 계산과 피난 시뮬레이션의 결과를 비교함에 따라 수 계산 시에 소수점 이하의 수로 인해 발생하는 계산의 오차 를 줄이고 본래의 목적인 순 피난시간을 살펴보고자 주요 요인을 제외한 일부 요인들은 단순화하여 아래와 Table 1 과 같은 인위적인 조건 하에 해석하였다.

재실자들의 신체기준은 청년의 나이대(18 65세)를 기준 으로 해당 연령의 한국인의 평균 어깨너비를 적용하여 Figure 5와 같이 $377.57 \mathrm{~mm}$ 로 적용하였다.

\section{3. 피난 시뮬레이션 결과 및 고찰}

본 장에서는 앞서 살펴본 국내와 해외의 피난관련 기준 을 실제 건축물에 적용하여 각 기준별 보행거리와 피난시 간을 비교하고자 시뮬레이션과 수 계산을 통하여 계산하였 다. 또한, 본 논문의 목적인 실제와 유사한 피난시간을 도 출을 도모하고 피난자들의 안전을 보장하기 위해 악조건의 피난 시나리오를 가정한 보행거리 측정 기준을 제시하고자 
Table 1. Simulation Conditions

\begin{tabular}{|c|c|c|}
\hline \multicolumn{2}{|c|}{ Sortation } & Contents \\
\hline \multicolumn{2}{|c|}{ The number of occupants } & 1 \\
\hline \multicolumn{2}{|c|}{ Interior finishing material } & Semi-non combustion \\
\hline \multirow{3}{*}{$\begin{array}{l}\text { Boundary } \\
\text { layer width }\end{array}$} & Doorway & $150 \mathrm{~mm}$ \\
\hline & Wall, Obstacle & $100 \mathrm{~mm}$ \\
\hline & Corridor & $200 \mathrm{~mm}$ \\
\hline
\end{tabular}

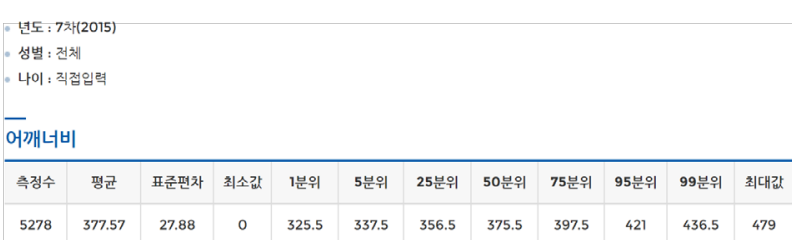

Figure 5. Average shoulder width for young people aged 18 to $65^{(5)}$.

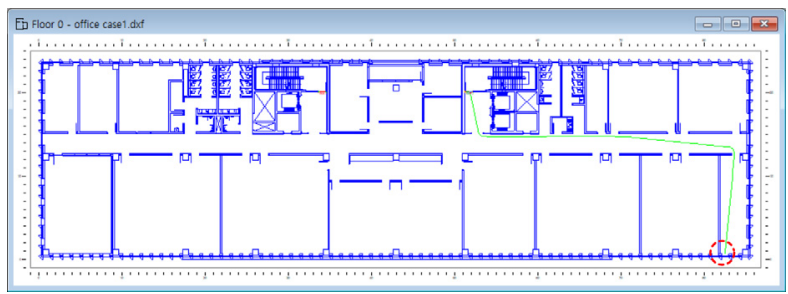

Figure 6. Maximum travel distance point (Business facility).

개선안을 수립하고 개선안을 적용한 시뮬레이션을 수행하 여 결과를 비교하였다.

\section{1 국내법 기준}

\subsection{1 업무시설}

SIMULEX를 이용하여 측정한 업무시설에서의 보행거리 최대 지점과 피난경로는 아래 Figure 6의 원 및 동선으로 표현하였다.

업무시설에서 국내법 기준을 적용한 피난 시뮬레이션 조건은 Table 2와 같이 경계층 폭을 적용하지 않고 실제 도 면에서 측정되는 값과 동일한 값을 적용하였다.

위와 같은 국내법 기준으로 업무시설에서 시뮬레이션 수행한 결과, Figure 7과 같이 당해 시뮬레이션에서 피난자 의 거실에서 계단실까지의 보행거리는 $48.6 \mathrm{~m}$ 로 나타났고 이 거리를 피난하기 위한 피난시간은 $41.8 \mathrm{~s}$ 가 소요되었다.

\subsection{2 판매시설}

앞서 업무시설에서 수행한 방법과 같이 SIMULEX를 이 용하여 판매시설에서의 보행거리 최대 지점을 해석한 결과 를 아래 Figure 8과 같이 최대 지점과 피난경로를 원 및 동 선으로 표현하였다.

판매시설에서 국내법 기준을 적용한 시뮬레이션 조건은
Table 2. Application Conditions for Evacuation Simulation of Business Facilities (Domestic Law)

\begin{tabular}{c|c|c|c|c}
\hline \multirow{2}{*}{ Sortation } & \multicolumn{4}{|c}{ Business Facilities } \\
\cline { 2 - 5 } & $\begin{array}{c}\text { Roon exit } \\
\text { width }\end{array}$ & $\begin{array}{c}\text { Obstacle } \\
\text { (Wall) }\end{array}$ & $\begin{array}{c}\text { Corridor } \\
\text { width }\end{array}$ & $\begin{array}{c}\text { Stairway } \\
\text { exit width }\end{array}$ \\
\hline \hline Case 1 & $975 \mathrm{~mm}$ & $0 \mathrm{~mm}$ & $2,350 \mathrm{~mm}$ & $840 \mathrm{~mm}$ \\
\hline
\end{tabular}

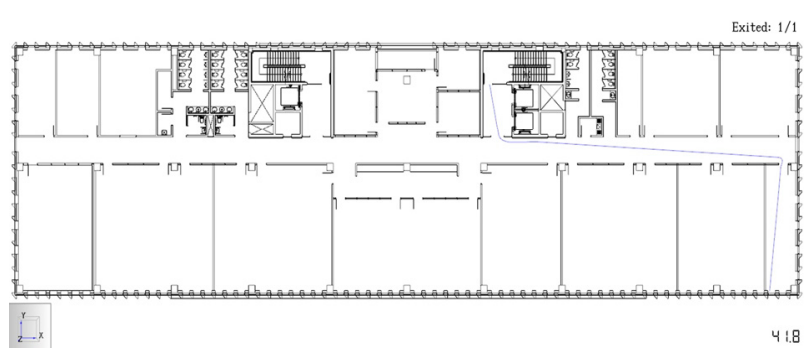

Figure 7. Business facility evacuation simulation result (Domestic law).

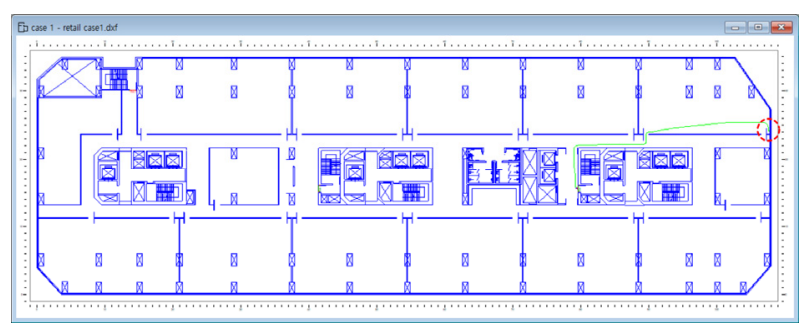

Figure 8. Maximum travel distance point (Sales facility).

Table 3. Application Conditions for Evacuation Simulation of Sales Facilities (Domestic Law)

\begin{tabular}{c|c|c|c|c}
\hline \multirow{2}{*}{ Sortation } & \multicolumn{4}{|c}{ Sales facilities } \\
\cline { 2 - 5 } & $\begin{array}{c}\text { Roon exit } \\
\text { width }\end{array}$ & $\begin{array}{c}\text { Corridor } \\
\text { width }\end{array}$ & $\begin{array}{c}\text { Corridor } \\
\text { width } \\
\text { (Open exit) }\end{array}$ & $\begin{array}{c}\text { Stairway } \\
\text { exit width }\end{array}$ \\
\hline \hline Case 1 & $825 \mathrm{~mm}$ & $1,800 \mathrm{~mm}$ & $1,000 \mathrm{~mm}$ & $840 \mathrm{~mm}$ \\
\hline
\end{tabular}

아래 Table 3과 같이 경계층 폭을 적용하지 않고 실제 도면 에서 측정되는 값과 동일한 값을 적용하였다.

Table 3에서 복도 폭은 악조건을 상정하여 출구가 열려있 는 상태에서의 복도 폭으로 적용하여 계산하였고, 국내법 기준으로 판매시설에서 시뮬레이션 수행한 결과는 Figure 9 와 같이 피난자의 위치에서 계단실까지의 보행거리는 37.7 $\mathrm{m}$ 로 나타났고, 소요된 시간은 $33.5 \mathrm{~s}$ 로 계산되었다.

\subsection{SFPE Handbook 기준}

\subsection{1 업무시설}

업무시설에서 Table 2에 제시한 SFPE Handbook의 경계 층 폭의 개념을 도입하여 출입구, 벽, 복도 등 각 피난 요소 의 유효 폭을 계산한 결과를 Table 4와 같이 나타냈다.

위와 같이 SFPE Handbook에서 제시하는 경계층 폭을 기 


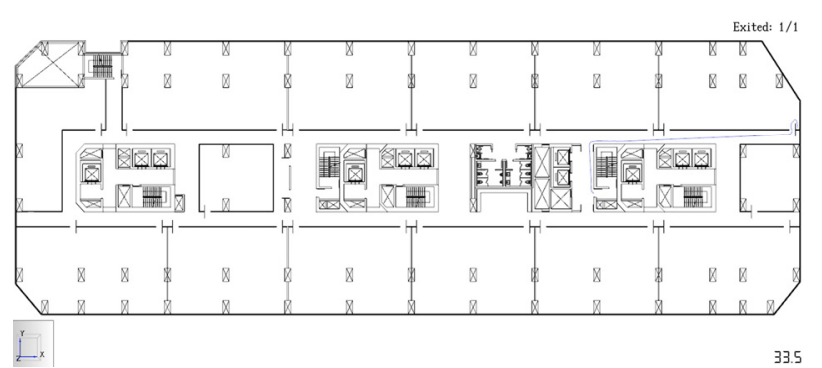

Figure 9. Sales facility evacuation simulation result (Domestic law).

Table 4. Application Conditions for Evacuation Simulation of Business Facilities (SPFE Handbook)

\begin{tabular}{c|c|c|c|c}
\hline \multirow{2}{*}{ Sortation } & \multicolumn{4}{|c}{ Business facilities } \\
\cline { 2 - 5 } & $\begin{array}{c}\text { Roon exit } \\
\text { width }\end{array}$ & $\begin{array}{c}\text { Obstacle } \\
\text { (Wall) }\end{array}$ & $\begin{array}{c}\text { Corridor } \\
\text { width }\end{array}$ & $\begin{array}{c}\text { Stairway } \\
\text { exit width }\end{array}$ \\
\hline \hline Case 2 & $675 \mathrm{~mm}$ & $100 \mathrm{~mm}$ & $1,950 \mathrm{~mm}$ & $540 \mathrm{~mm}$ \\
\hline
\end{tabular}

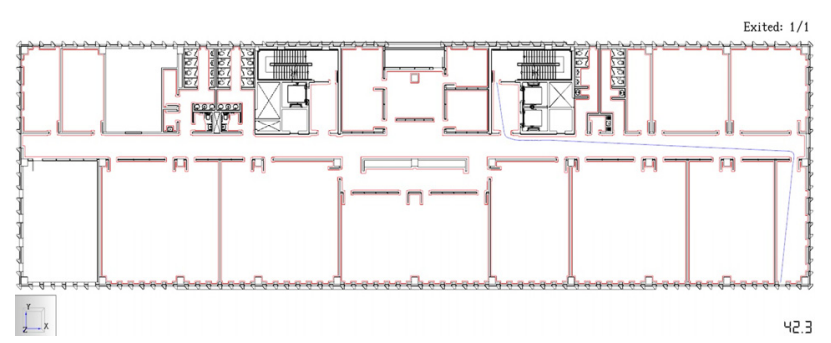

Figure 10. Business facility evacuation simulation result (SFPE handbook).

존 요소들의 경계에서 경계층 폭만큼 바깥으로 돌출시켜 Figure 10 에서와 같이 나타내었다.

금번 시뮬레이션의 결과는 피난자의 거실에서 계단실까 지의 보행거리는 $49.2 \mathrm{~m}$ 로 계산되었고 피난시간은 $42.3 \mathrm{~s}$ 가 소요되었다. 보행거리와 피난시간이 늘어나긴 했지만, 피 난자를 1 명으로 설정함에 따라 피난 인원이 많은 경우에 나타나는 병목현상 등과 같이 출입구의 피난 흐름에 영향 을 끼치는 요소가 없기 때문에, 시간적으로 국내 기준 시뮬 레이션 결과와 큰 차이는 확인되지 않았다.

\subsection{2 판매시설}

판매시설에서 Table 3에 제시한 SFPE Handbook의 경계 층 폭의 개념을 도입하여 출입구, 벽, 복도 등 각 피난경로 요소의 유효 폭을 계산한 결과는 Table 5 와 같이 나타냈다.

위와 같이 경계층 폭 개념을 도입한 유효 폭을 적용하여 판매시설에서 시뮬레이션 수행한 결과는 Figure 11과 같다.

위 그림에서도 업무시설에서와 마찬가지로 기존 요소들 의 경계에서 경계층 폭만큼 바깥으로 돌출시켜 적색으로 나타내었다. 시뮬레이션의 결과로 피난자의 보행거리는 $38.7 \mathrm{~m}$ 로 계산되었고 피난시간은 $34.0 \mathrm{~s}$ 가 소요되었다. 금 번 시뮬레이션 역시 피난자를 1명으로 계산했기 때문에,
Table 5. Application Conditions for Evacuation Simulation of Sales Facilities (SPFE Handbook)

\begin{tabular}{c|c|c|c|c}
\hline \multirow{2}{*}{ Sortation } & \multicolumn{4}{|c}{ Sales Facilities } \\
\cline { 2 - 5 } & $\begin{array}{c}\text { Roon Exit } \\
\text { width }\end{array}$ & $\begin{array}{c}\text { Corridor } \\
\text { width }\end{array}$ & $\begin{array}{c}\text { Corridor } \\
\text { width } \\
\text { (Open exit) }\end{array}$ & $\begin{array}{c}\text { Stairway } \\
\text { exit width }\end{array}$ \\
\hline \hline Case 2 & $525 \mathrm{~mm}$ & $1,400 \mathrm{~mm}$ & $650 \mathrm{~mm}$ & $540 \mathrm{~mm}$ \\
\hline
\end{tabular}

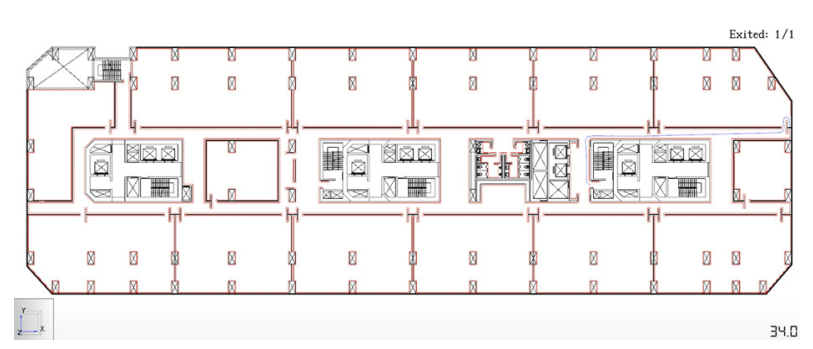

Figure 11. Sales facility evacuation simulation result (SFPE handbook).

출입구의 피난흐름에 영향을 끼치는 요소가 적어서 피난시 간에 큰 차이는 확인되지 않았다.

\section{3 피난안전검증법 기준}

피난안전검증법 기준으로 출구까지의 보행시간을 계산 할 때는 해당 층의 재실자의 위치가 직통계단까지의 보행 거리가 가장 먼 지점에 있다는 것을 가정하고 이 재실자가 직통계단에 도달하는 시간을 계산한다. 화재실이 직통계단 에 직접 면해있거나 화재실이 직접 지상으로 통하는 경우 에는 직통계단 또는 지상으로 통하는 출구 중 최대 폭인 것 1 개는 없는 것으로 계산한다. 이것은 층 피난이 이뤄지 는 단계에서는 화재실 출구 중 1 개소는 사용할 수 없는 상 황까지 고려한 것을 나타내며 계산방법은 식 (1) ${ }^{(6)}$ 과 같다.

$$
t_{\text {travel }}=\max \left(\sum \frac{l_{1}}{v}\right)
$$

$t_{\text {travel }}=$ 층에 있는 사람이 당해 층의 각 실에서 직통계단 중 하나에 도달하는데 필요한 보행시간

$l_{1}=$ 당해 층의 각 실에서 직통계단으로 향하는 출구(당 해 화재실이 당해 층에 설치되어 있는 직통계단에 직접 통 하는 실인 경우에는 당해 화재실의 직통계단으로 통하는 출구 중 그 폭이 최대인 것을 제외한다.)중 하나에 도달하 는데 걸리는 보행거리 $(\mathrm{m})$

$$
v=\text { 보행속도 }(\mathrm{m} / \mathrm{s})
$$

이때 적용하는 보행속도는 Table 6 과 같이 건축물 및 거 실의 용도별, 건축물 부분의 종류에 따라 보행속도 값을 적 용하도록 제시하고 있다. 
Table 6. Travel Speed by Building's Purpose ${ }^{(7)}$

\begin{tabular}{c|c|c|c}
\hline \multirow{2}{*}{$\begin{array}{c}\text { Use of building or } \\
\text { room }\end{array}$} & Component & $\begin{array}{c}\text { Evacuation } \\
\text { direction }\end{array}$ & $\begin{array}{c}\text { Travel } \\
\text { speed } \\
(\mathrm{m} / \mathrm{min})\end{array}$ \\
\hline \hline \multirow{2}{*}{$\begin{array}{c}\text { Sales facilities or } \\
\text { other similar use }\end{array}$} & Stairway & Upward & 27 \\
\cline { 3 - 4 } & $\begin{array}{c}\text { Other } \\
\text { components }\end{array}$ & Downward & 36 \\
\hline \multirow{2}{*}{$\begin{array}{c}\text { Business facilities or } \\
\text { other similar use }\end{array}$} & Stairway & Upward & 60 \\
\cline { 2 - 4 } & Other & Downward & 47 \\
\hline
\end{tabular}

Table 7. Application Conditions for Evacuation Simulation of Business Facilities (Evacuation Safety Verification Method)

\begin{tabular}{c|c|c}
\hline \multirow{2}{*}{ Sortation } & \multicolumn{2}{|c}{ Travel distance $(\mathrm{m})$} \\
\cline { 2 - 3 } & $\begin{array}{c}\text { Refugee location } \\
\text { Room exit }\end{array}$ & $\begin{array}{c}\text { Room exit } \\
\text { Stair hall entrance }\end{array}$ \\
\hline \hline Case 3 & 13.69 & 39.56 \\
\hline
\end{tabular}

\subsection{1 업무시설}

피난안전검증법 기준으로 피난시간을 계산하기 위해 도 면에서의 각 요소의 면적과 1 차 안전지대인 계단실까지의 보행거리 등 입력값을 Table 7과 같이 측정하였다.

피난자의 위치에서 계단실 출구까지 이르는 최대 거리 는 $53.25 \mathrm{~m}$ 로 측정되었고, Table 6에 따라 보행속도는 78 $\mathrm{m} / \mathrm{min}$ 을 식 (2)에 대입하여 계산했다.

$$
t_{\text {travel }}=53.25 / 78=0.68 \min (40.8 \mathrm{~s})
$$

\subsection{2 판매시설}

업무시설과 같이 피난안전검증법 기준으로 피난시간을 계산하기 위해 도면에서의 계산한 입력값을 다음 Table 8 과 같이 나타내었다.

피난자의 위치에서 계단실 출구까지 이르는 최대 거리 는 $39.56 \mathrm{~m}$ 로 측정되었고, Table 6에 따라 보행속도는 60 $\mathrm{m} / \mathrm{min}$ 을 식 (3)에 대입하여 계산했다.

$$
t_{\text {travel }}=39.56 / 60=0.66 \mathrm{~min}
$$

\section{4 개선안 방법}

국내에서 일반적으로 행해지는 피난 시뮬레이션들은 재 실자의 해당 위치에서 출구까지 최단거리 즉, 대각선으로 이동하는 시간을 측정한다. 그러나 이런 단순한 기준으로 행해지는 계산 방법은 건축물 용도에 따라 피난동선에 장 애물이 많은 경우, 화재 위치에 따라 열과 연기로 최단거리 에 있는 출구를 이용할 수 없는 경우 등 다양한 화재 시나
Table 8. Application Conditions for Evacuation Simulation of Sales Facilities (Evacuation Safety Verification Method)

\begin{tabular}{c|c|c}
\hline \multirow{2}{*}{ Sortation } & \multicolumn{2}{|c}{ Travel distance $(\mathrm{m})$} \\
\cline { 2 - 3 } & $\begin{array}{c}\text { Refugee location } ~ \\
\text { Room exit }\end{array}$ & $\begin{array}{c}\text { Room exit } \\
\text { Stair hall entrance }\end{array}$ \\
\hline \hline Case 3 & 3.01 & 36.55 \\
\hline
\end{tabular}

Table 9. A Proposal for Improvement of Travel Distance Measurement Criteria

\begin{tabular}{c|l}
\hline Sort & \multicolumn{1}{|c}{ Contents } \\
\hline (1) & $\begin{array}{l}\text { Start at the farthest location from the exit (where the } \\
\text { walking distance is the longest) }\end{array}$ \\
\hline (2) & Measure on floor or other pedestrian surfaces \\
\hline (3) & $\begin{array}{l}\text { Measure along the centerline of the natural path of } \\
\text { travel }\end{array}$ \\
\hline (4) & $\begin{array}{l}\text { Curving around any corners or obstructions, with a } \\
\text { 12in.(305mm) clearance therefrom }\end{array}$ \\
\hline (5) & $\begin{array}{l}\text { Measure on the plane of the tread end of the open exit } \\
\text { access ramp or the open exit access stair. }\end{array}$ \\
\hline (6) & Measure at the beginning of the evacuation passage \\
\hline (7) & $\begin{array}{l}\text { Assume that in a room with many obstacles in it, such } \\
\text { as classrooms and sales facilities, evacuating along the } \\
\text { wall from the location of the refugee }\end{array}$ \\
\hline (8) & $\begin{array}{l}\text { If there are two or more exits, it is assumed that one } \\
\text { with a large exit width cannot be used } \\
\text { (If the exit width is the same, except for the exit closest } \\
\text { to the direct stairs) }\end{array}$ \\
\hline
\end{tabular}

리오를 포괄적으로 해석하기에는 무리가 있는 실정이다.

이에 반해 NFPA 101에서는 피난통로까지의 보행거리 측 정 시, 동선을 통로의 중앙으로 규정하고, 코너와 장애물 주 변에서 일정 폭을 두어 측정하도록 기준을 제시하고 있다.

NFPA 101와 SFPE Handbook, 피난안전검증법을 비교 검 토한 결과, 최악의 경우를 고려하여 안전을 확보할 수 있으 면서 합리적인 피난시간을 계산하기 위해 NFPA $101^{(8)}$ 을 보완하여 Table 9와 같은 보행거리 측정 기준을 제안하고 자 한다.

Table 9의 측정 기준을 적용함으로써, 기존에 단순히 피 난시간을 최단거리로 이동하는 시간으로 해석하는 조건에 서 벗어나 보행거리는 통로의 중앙으로 규정하고 코너와 장애물 주변에 일정 폭을 두어 측정하는 등의 피난동선에 구체적인 조건들을 적용하고, 장애물이 많은 장소나 출구 가 2 개 이상인 경우에서의 벽을 따라 피난하거나 출구는 1 개만 이용하는 등의 해석 조건을 마련함으로써 다양한 화 재 시나리오를 포괄적으로 해석할 수 있게 된다.

\subsection{1 업무시설}

본 논문에서 제시하는 보행거리 측정 기준 개선안으로 
Table 10. Application Conditions for Evacuation Simulation of Business Facilities (A Proposal for Improvement)

\begin{tabular}{c|c|c|c|c|c}
\hline \multirow{2}{*}{ Sortation } & \multicolumn{5}{|c}{ Business facilities (mm) } \\
\cline { 2 - 6 } & $\begin{array}{c}\text { Roon } \\
\text { exit } \\
\text { width }\end{array}$ & $\begin{array}{c}\text { Obstacle } \\
\text { (Wall) }\end{array}$ & $\begin{array}{c}\text { Corridor } \\
\text { width }\end{array}$ & $\begin{array}{c}\text { Stairway } \\
\text { exit } \\
\text { width }\end{array}$ & $\begin{array}{c}\text { Corner } \\
\text { bypass } \\
\text { width }\end{array}$ \\
\hline \hline Case 4 & 675 & 100 & 1,950 & 540 & 305 \\
\hline
\end{tabular}

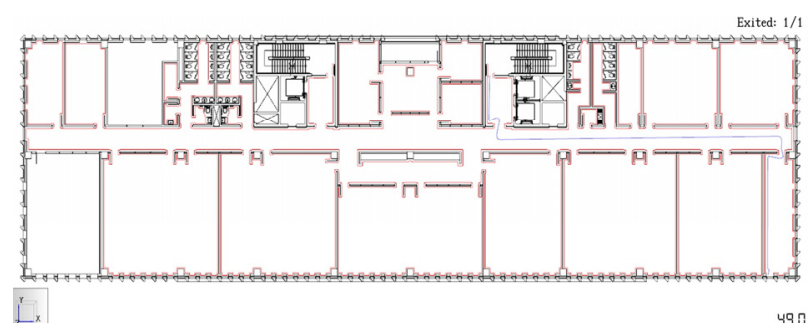

Figure 12. Business facility evacuation simulation result (A proposal for improvement).

피난시간을 측정하고자, Table 10 과 같이 각 요소에 경계층 폭을 도입하고 코너에서는 12 in $(305 \mathrm{~mm})$ 의 여유를 두었 으며, 화원 및 장애물의 위치 등 변수를 고려하여 최악의 조건인 경우를 상정하여 피난자는 벽을 따라 피난하는 것 으로 해석하였다.

보행거리 측정 기준 개선안을 적용하여 업무시설에서 피난 시뮬레이션 수행한 결과는 Figure 12 와 같이 피난자가 거실에서 계단실까지의 벽을 따라 피난한 보행거리는 54.3 $\mathrm{m}$ 로 나타났고 피난시간은 $49.0 \mathrm{~s}$ 가 소요되었다.

개선안을 적용한 시뮬레이션에서는 최단거리로 대피하 지 못하고 벽을 따라 이동하는 악조건을 상정하여 계산한 만큼 보행거리와 피난시간이 대폭 늘어난 것을 확인할 수 있었다.

\subsection{2 판매시설}

업무시설의 경우와 마찬가지로 Table 11 과 같이 각 요소 에 경계층 폭을 도입하고 코너에서는 $12 \mathrm{in}(305 \mathrm{~mm})$ 의 여 유를 두었으며, 화원 및 장애물의 위치 등 변수를 고려하여 피난자는 벽을 따라 피난하는 것으로 해석하였다.

본 논문에서 제시하는 보행거리 측정 기준 개선안으로 판 매시설에서 피난 시뮬레이션 수행한 결과는 Figure 13 과 같 이 피난자가 실에서 계단실까지의 벽을 따라 피난한 보행거 리는 $41.3 \mathrm{~m}$ 로 계산되었고 피난시간은 $37.8 \mathrm{~s}$ 가 소요되었다.

업무시설의 사례와 마찬가지로 최단거리가 아닌 벽을 따라 이동한 만큼 보행거리와 피난시간이 늘어났고 이 역 시 피난자들이 많은 경우에는 더 큰 차이를 보일 것으로 예상된다.
Table 11. Application Conditions for Evacuation Simulation of Sales Facilities (A Proposal for Improvement)

\begin{tabular}{c|c|c|c|c|c}
\hline \multirow{2}{*}{ Soration } & \multicolumn{5}{|c}{ Sales Facilities } \\
\cline { 2 - 6 } & $\begin{array}{c}\text { Roon } \\
\text { exit } \\
\text { width }\end{array}$ & $\begin{array}{c}\text { Corridor } \\
\text { width }\end{array}$ & $\begin{array}{c}\text { Corridor } \\
\text { width } \\
\text { (Open exit) }\end{array}$ & $\begin{array}{c}\text { Stairway } \\
\text { exit } \\
\text { width }\end{array}$ & $\begin{array}{c}\text { Corner } \\
\text { bypass } \\
\text { width }\end{array}$ \\
\hline \hline Case 4 & 525 & 1,400 & 650 & 540 & 305 \\
\hline
\end{tabular}

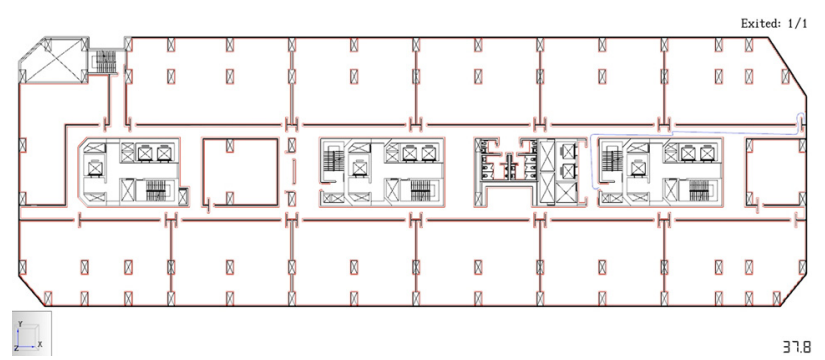

Figure 13. Sales facility evacuation simulation result (A proposal for improvement).

Table 12. Result Table for Travel Distance and Evacuation Time

\begin{tabular}{c|c|c|c|c}
\hline \multirow{2}{*}{ Sortation } & \multicolumn{2}{|c|}{ Business facility } & \multicolumn{2}{c}{ Sales facility } \\
\cline { 2 - 5 } & $\begin{array}{c}\text { Travel } \\
\text { distance }\end{array}$ & $\begin{array}{c}\text { Evacuation } \\
\text { time }\end{array}$ & $\begin{array}{c}\text { Travel } \\
\text { distance }\end{array}$ & $\begin{array}{c}\text { Evacuation } \\
\text { time }\end{array}$ \\
\hline \hline Domestic law & $48.6 \mathrm{~m}$ & $41.8 \mathrm{~s}$ & $37.7 \mathrm{~m}$ & $33.5 \mathrm{~s}$ \\
\hline $\begin{array}{c}\text { Evacuation } \\
\text { safety } \\
\text { verification } \\
\text { method }\end{array}$ & $53.3 \mathrm{~m}$ & $40.8 \mathrm{~s}$ & $39.6 \mathrm{~m}$ & $39.6 \mathrm{~s}$ \\
\hline SFPE handbook & $49.2 \mathrm{~m}$ & $42.3 \mathrm{~s}$ & $38.7 \mathrm{~m}$ & $34.0 \mathrm{~s}$ \\
\hline $\begin{array}{c}\text { Improvement } \\
\text { proposal }\end{array}$ & $54.3 \mathrm{~m}$ & $49.0 \mathrm{~s}$ & $41.3 \mathrm{~m}$ & $37.8 \mathrm{~s}$ \\
\hline Average & $51.4 \mathrm{~m}$ & $43.5 \mathrm{~s}$ & $39.3 \mathrm{~m}$ & $36.2 \mathrm{~s}$ \\
\hline
\end{tabular}

\section{5 결과 및 고찰}

업무시설과 판매시설의 보행거리 측정 기준에 따른 보 행거리와 피난시간 결과를 종합한 결과는 Table 12 와 같이 국내법 기준으로 계산한 경우의 보행거리와 피난시간이 가 장 적게 나타났으며, 개선안을 적용한 보행거리와 피난시 간이 가장 크게 나타났다.

보행거리의 경우, $\mathrm{SFPE}$ 는 경계층 폭을 적용함으로써 국 내법 기준에 비해 약간 늘어났고 피난안전검증법에서 보행 거리는 방의 각 부분에서 출구까지의 가장 긴 보행거리를 적용하기 때문에 최단거리가 아닌 수직방향으로 움직이는 것으로 측정하여 가장 길게 계산된 것으로 분석되었다.

결론적으로 국내법에서는 보행거리의 측정 기준이 명시 되어 있지 않기 때문에 보행거리 및 피난시간 결과는 최악 의 조건을 적용한 개선안 대비 업무시설과 판매시설에서 평균 $4.7 \mathrm{~m}, 5.8 \mathrm{~s}$ 가장 큰 차이를 보였고, 출구 유효 폭의 
적용 여부에 따라서도 약 $0.8 \mathrm{~m}, 0.5 \mathrm{~s}$ 의 차이를 보였다.

이 결과를 통해 단순 최단거리를 이용한 보행거리 산정 을 지양하고 다양한 화재 시나리오에 대응할 수 있는 악조 건을 상정한 보행거리 기준의 필요성과 건축법 시행령에서 규정하는 '유효' 폭이라는 단어의 본래 취지에 맞도록 피난 자가 이용할 수 있는 유효 폭을 산정하여 피난시간을 계산 해야 하며 본 논문에서 제안하는 방법으로 피난시간을 계 산하고, ASET (피난허용시간)을 늘리고 RSET (필요피난시 간)을 단축할 수 있는 방안에 대한 다양한 연구의 필요성 을 주장하는 바이다.

\section{4. 결 론}

본 연구는 국내 및 해외 피난 관련 기준을 비교 검토하 여 유효한 피난시간 확보를 위한 국내 보행거리와 출구 폭 에 대한 기준 정립을 통한 개선안 수립에 대해 연구하여 다음과 같은 피난시간 계산 기준을 도출하였다.

첫째, 실제 상황에서는 장애물과 화재 위치에 따라 최단 거리로 보행할 수 없을 가능성이 있기 때문에 보행거리는 현재와 같은 최단거리가 아닌 출구 및 보행로의 중앙선을 따라 측정해야 한다.

둘째, 교실 및 판매시설 등 내부에 장애물이 많은 장소 에서는 화원과 장애물의 불정형성을 고려하여 일반적인 보 행로가 아닌 벽을 따라 피난하는 것으로 가정해야 한다.

셋째, 실의 출구가 2 개 이상인 경우, 화재가 충분히 진행 된 것으로 상정하여 출구 폭이 큰 하나의 것은 피난이 불 가한 것으로 가정해야 한다.

넷째, 일반적으로 피난자들은 피난 경로의 전체 폭을 점 유하지 않기 때문에 출구 등(계단, 복도, 출구)의 특성에 따 라 경계층 폭을 제외한 피난에 실제로 이용하는 유효 폭을 반영하여 피난시간을 산정해야 한다.

이 연구의 목적은 현재 기준보다 더 현실적이고 실제 피 난 상황에 대비한 안전한 피난계획을 수립할 수 있도록 가 혹한 기준의 적용이 필요함을 나타내는 것을 목적으로 하
였으며, 이 연구를 시작으로 나날이 발전하는 건축 관련 기 술에 발맞춘 피난 관련 법률의 개정이 이뤄지고 재실자들 의 최소한의 안전을 보장하는 피난 설계에 대한 심도있는 연구의 초석이 되길 바란다.

\section{References}

1. Ministry of Land, Infrastructure and Transport, "Enforcement Decree of the Building Act", 34.1-2 (2021).

2. Ministry of Land, Infrastructure and Transport, "Rules on the standards for evacuation, fire protection, etc. of buildings", 9.2( i - iii) (2020).

3. D. O'Connor, J. Bryan, G. Hartzell, G. Proulx, E. Cable, F. Hsu, S. Smith, R. Fahy et al., "Engineering Guide Human Behavior in Fire", SFPE, PP. 31-32 (2003).

4. A. J. Blair, "THE EFFECT OF STAIR WIDTH ON OCCUPANT SPEED AND FLOW OF HIGH RISE BUILDINGS", Master Degree Thesis of University of Maryland, pp. 5 (2010).

5. Korea Institute of Design Promotion, https://sizekorea.kr/ measurement-data/body (2021)

6. S. M. Lee, "A Study on the Method of Engineering Analysis about Architectural Elements for Evacuation Safety Assessment: Focused on Office Buildings", Doctor Degree Thesis of University of Seoul, pp. 117-118 (2012).

7. S. M. Lee, "A Study on the Method of Engineering Analysis about Architectural Elements for Evacuation Safety Assessment: Focused on Office Buildings", Doctor Degree Thesis of University of Seoul, p. 97 (2012).

8. W. E. Koffel, R. Cote, D. S. Collins, W. D. Holmes, H. Hopper, K. E. Isman, J. E. Kalie, Jr, G. H. McCall et al., 'NFPA 101 LIFE SAFETY CODE', National Fire Protection Association, pp. 79-80 (2014). 